\title{
HAEMODYNAMIC EFFECTS AND RECOVERY PROFILE WITH MIDAZOLAM AND PROPOFOL AS CO- INDUCTION AGENTS FOR DAY CARE SURGERY
}

\author{
Kosam Durga1, Kujur Shweta², Murthy Madhumita ${ }^{3}$
}

${ }^{1}$ Associate Professor, Department of Anaesthesia, Chhattisgarh Institute of Medical Sciences, Bilaspur, Chhattisgarh, India. ${ }^{2}$ Assistant Professor, Department of Anaesthesia, Chhattisgarh Institute of Medical Sciences, Bilaspur, Chhattisgarh, India. 3Professor, Department of Anaesthesia, Chhattisgarh Institute of Medical Sciences, Bilaspur, Chhattisgarh, India.

\section{ABSTRACT}

\section{BACKGROUND}

For ambulatory surgery, anaesthetic regimens used are primarily aimed at improving recovery from anaesthesia and shortening hospital stay. Propofol is the most popular day care anaesthetic agent. Propofol causes cardiovascular and respiratory depression at induction dose. Pre-dosing with a small dose of propofol or midazolam can reduce its induction dose and thereby its adverse effects.

Aim: The present study compared haemodynamic effects and recovery profile using propofol and midazolam as conduction agents.

\section{MATERIALS AND METHODS}

A randomised controlled study was conducted on 90 ASA I and II patients undergoing outpatient surgery. Patients were randomly allocated to receive $3 \mathrm{~mL}$ of normal saline (Group I), $0.4 \mathrm{mg} / \mathrm{kg}$ propofol 1\% (Group II) and $0.05 \mathrm{mg} / \mathrm{kg}$ of midazolam (Group III). Two minutes later propofol $1 \%$ infusion was started at the rate of $300 \mathrm{~mL} / \mathrm{hr}$ and LMA inserted. Vitals- HR, NIBP, SpO 2 , mouth opening, ease of LMA insertion and undesired responses to LMA insertion were noted. Postoperatively, time to spontaneous eye opening and time to discharge were assessed.

\section{RESULTS}

Administration of co-induction agent as well as propofol caused a significant fall in MAP and heart rate in all three groups with group II showing a greater fall than group I and group III $(\mathrm{p}<0.05)$. More patients in group I and II compared to group III showed movement on LMA insertion. Patients in group III took maximum time to open eyes (5.9 mins) compared to group I and group II $(\mathrm{p}<0.05)$. The time taken for return of coin counting skills as well as time for discharge was significantly longer in group III $(\mathrm{p}<0.05)$ compared to group I and group II.

\section{CONCLUSION}

Both propofol and midazolam pre-dosing reduce induction dose requirements of propofol. Midazolam co-induction showed more stable haemodynamics compared to propofol pre-dosing. However, it delayed psychomotor recovery by more than 20 mins. In situations where haemodynamic stability is paramount, midazolam co-induction is a better choice despite delayed discharge.

\section{KEY WORDS}

Anaesthesia, Day Care Surgery, Haemodynamic Stability, Induction Dose, Midazolam, Propofol.

HOW TO CITE THIS ARTICLE: Durga K, Shweta K, Madhumita M. Haemodynamic effects and recovery profile with midazolam and propofol as co-induction agents for day care surgery. J. Evolution Med. Dent. Sci. 2018;7(32):3565-3568, D0I: $10.14260 /$ jemds/2018/801

\section{BACKGROUND}

Propofol is the most popular day care anaesthetic agent. It has a good safety index, but when used as sole anaesthetic agent causes significant decrease in arterial blood pressure. With the aim to balance the ratio of desired versus adverse effects, the concept of co-induction ${ }^{1}$ came into practice, especially for outpatient anaesthesia. At the recommended induction dose of 2 - $2.5 \mathrm{mg} / \mathrm{kg}$ propofol can cause cardiovascular and respiratory depression. ${ }^{2-5}$ To avoid these cardiovascular and respiratory effects pre-dosing with small dose of propofol or midazolam before induction of anaesthesia are the two most commonly used co-induction

'Financial or Other Competing Interest': None.

Submission 25-06-2018, Peer Review 20-07-2018,

Acceptance 26-07-2018, Published 01-08-2018.

Corresponding Author:

Dr. Kujur Shweta,

A-13, Phase II, Vaishnavi Vihar,

Uslapur, Bilaspur-495001,

Chhattisgarh, India.

E-mail: shwetakujur08@gmail.com

DOI: $10.14260 /$ jemds/2018/801

\section{(c) (i) $(9)$}

techniques.6-8 However, the benefits in terms of haemodynamic instability have not been demonstrated in all the studies. ${ }^{8-13}$ Moreover, whether a small dose of midazolam can lead to a significant prolongation of discharge time also remains controversial.6,7,10 Therefore, the present study was planned to compare post-induction haemodynamic effects and recovery profile using propofol and midazolam as coinduction agents.

\section{MATERIALS AND METHODS}

This randomised controlled study was conducted at Chhattisgarh Institute of Medical Sciences, Bilaspur (CG) from December 2016 to November 2017. Following Institutional Ethics Committee approval and informed consent, 90 ASA I and II patients of either sex, aged 20 - 50 years admitted for short surgical procedures on an outpatient basis were included in this study. Patients were excluded if they were taking benzodiazepines, antidepressants or anti-seizure medications. A random number table was used to prepare sealed envelopes for group assignment. An assistant opened these envelopes and prepared the study drug. The investigators were blinded to the group assignment of each 
patient. Patients were not pre-medicated. The coin counting test was performed preoperatively to familiarise the patients with the test. In the operation theatre baseline measurement of arterial pressure, heart rate and arterial oxygen saturation were made using Multipara monitor. An IV cannula was inserted in non-dominant hand of all the patients and pentazocine $0.3 \mathrm{mg} / \mathrm{kg}^{\prime} 1$ was injected. After 3 mins the patients were randomly allocated to receive: $3 \mathrm{~mL}$ of normal saline (group 1), $0.4 \mathrm{mg} / \mathrm{kg}^{11}$ propofol $1 \%$ (group II) and $0.05 \mathrm{mg} / \mathrm{kg}$ of midazolam (group III). Two minutes later, propofol $1 \%$ infusion at the rate $300 \mathrm{~mL} / \mathrm{hr}$ was started. Propofol infusion was terminated when a $50 \mathrm{~mL}$ loaded syringe was held between the thumb and ring finger of dominant hand of the patient dropped. An experienced anaesthetist utilising Brain's technique then inserted an appropriate size LMA. Further boluses of propofol $(0.25 \mathrm{mg} / \mathrm{kg}$ every $15 \mathrm{secs})$ were administered if the initial dose was inadequate for LMA insertion. Thereafter, anaesthesia was maintained with $66 \%$ NO2 and $0.5-1 \%$ halothane in oxygen. Intraoperatively, the patients were monitored for non-invasive blood pressure, heart rate and arterial oxygen saturation. These parameters were noted after injection of pentazocine, injection of co-induction of anaesthesia and every min up to 5 mins after LMA insertion and thereafter. The mouth opening for LMA insertion was graded on a 3-point score with 1- full (Full relaxed jaw), 2partial (Some resistance) and 3- impossible. The ease of LMA insertion was graded as 1-easy (placement at $1^{\text {st }}$ attempt), 2some difficulty (placement on $2^{\text {nd }}$ attempt) and 3- difficult (More than two attempts). Any undesired response to LMA insertion like movement, coughing, gagging and laryngospasm were also recorded. The total dose of propofol used for induction and additional doses of propofol used for LMA insertion were recorded in all the groups. Postoperatively, time to spontaneous eye opening, time to discharge from hospital (based on post anaesthesia discharge scoring system for determining home readiness) ${ }^{14}$ and psychomotor test for street fitness ${ }^{14}$ were assessed. The coin counting test was performed in the recovery room every 30 mins upto $2 \mathrm{hrs}$. for assessing the home readiness. A mean of 3 readings were recorded in the pre-anaesthesia room and again post-operatively when the patient could sit up unaided without feeling dizzy or nauseated. Post-operative pain relief was provided with diclofenac sodium IV.

\section{The Coin Counting Test ${ }^{15}$}

This is a pool of coins of four different, but small denominations (having value of $1,2,5$ and 10 units of currency). On three successive occasions the patient is asked to count the monetary value of seven of the coins, which have been chosen at random and placed in his/ her hand. The average time it takes for the patient to count the monetary value is recorded. The test assesses the return of sensory perception, acuity of vision, ability to quickly change eye fixation, fine muscle co-ordination, higher intellectual faculties required for mathematical performance, sustained concentration and word naming.

\section{Statistical Analysis}

Results are expressed as mean and SD. Numerical data were analysed by SPSS 21.0 Version. One-Way analysis of variance
(ANOVA) with post-hoc test to find statistical significance amongst three groups.

\section{RESULTS}

The three groups were similar in respect to age, gender, weight, ASA status and duration of surgery (Table 1).

\begin{tabular}{|c|c|c|c|c|}
\hline & Age (yrs.) & $\begin{array}{c}\text { Weight } \\
\text { (kg) }\end{array}$ & $\begin{array}{c}\text { Gender } \\
\text { (M: F) }\end{array}$ & $\begin{array}{c}\text { Duration of } \\
\text { Surgery (mins) }\end{array}$ \\
\hline Group I & $42.1 \pm 12.8$ & $61.8 \pm 8.1$ & 18.12 & $47 \pm 13.4$ \\
\hline Group II & $41.1 \pm 13.2$ & $61.3 \pm 8.4$ & 18.12 & $46.5 \pm 13.8$ \\
\hline Group III & $40.2 \pm 11.9$ & $56.9 \pm 10.5$ & 20.10 & $46.5 \pm 13.2$ \\
\hline \multicolumn{4}{|c|}{ Table 1. Demographic Data (mean \pm SD) } \\
\hline
\end{tabular}

The mean dose of propofol required for induction of anaesthesia was significantly greater in group I, with group II and III showing a progressive decrease $(\mathrm{p}<0.001)$ (Table 2).

\begin{tabular}{|c|c|c|c|}
\hline & $\begin{array}{c}\text { Group I } \\
(\mathbf{n = 3 0 )}\end{array}$ & $\begin{array}{c}\text { Group II } \\
(\mathbf{n = 3 0 )}\end{array}$ & $\begin{array}{c}\text { Group III } \\
\text { (n=30) }\end{array}$ \\
\hline Initial dose (mg) & $117.8 \pm 15.8$ & $94.6 \pm 15.9^{*}$ & $58.6 \pm 16.3+\#$ \\
\hline $\begin{array}{c}\text { Additional dose } \\
(\mathrm{mg})\end{array}$ & $14.6 \pm 21.9$ & $10.1 \pm 22$ & $7.4 \pm 11$ \\
\hline Total dose (mg) & $132.5 \pm 23.1$ & $100.5 \pm 15.2 *$ & $66.7 \pm 15.8+\#$ \\
\hline $\begin{array}{c}\text { Dose requirement } \\
\text { (mg/kg) }\end{array}$ & $2.14 \pm 0.24$ & $1.66 \pm 0.28^{*}$ & $1.16 \pm 0.14+\#$ \\
\hline Table 2. Average Consumption of Propofol (mean \pm SD) \\
\hline
\end{tabular}

*I vs II, +I vs III, \#II vs III $\mathrm{p}<0.001$

All the three groups showed a significant but comparable fall in MAP from the baseline value after injection of pentazocine. A fall in MAP was observed in all three groups after the injection of co-induction agent with group II showing a greater fall than group III $(\mathrm{p}<0.05)$, whereas the fall was comparable between group I and group II. Further fall in MAP was observed in all the three groups following injection of co-induction agent and induction of anaesthesia with propofol infusion and upto 5 mins after insertion of LMA. Patients in midazolam co-induction group showed better cardiovascular stability and the fall in MAP was significantly lesser $(p<0.05)$ than in propofol pre-dosing and saline group at all points of time. The maximum reduction in MAP was 7\% from baseline in midazolam propofol group, while it was $18 \%$ and $23 \%$ in propofol pre-dosing (Table 3 ). A significant fall in HR from the basal value was observed in all the three groups following injection of pentazocine. However, there was no intergroup difference following injection of co-induction agent as well as induction agent and upto 5 mins after LMA insertion. The fall was significantly greater in group II compared to group I and group III $(p<0.05)$, whereas in group I and III the fall was comparable at all points of time.

\begin{tabular}{|c|c|c|c|}
\hline & $\begin{array}{c}\text { Group I } \\
\text { (n=30) }\end{array}$ & $\begin{array}{c}\text { Group II } \\
\text { (n=30) }\end{array}$ & $\begin{array}{c}\text { Group III } \\
\text { (n=30) }\end{array}$ \\
\hline Baseline MBP (mmHg) & $92.6 \pm 10.7$ & $94.7 \pm 10.9$ & $97.2 \pm 10.4$ \\
\hline Lowest MBP (mmHg) & $75.7 \pm 9.0$ & $72.8 \pm 9.4$ & $89.9 \pm 8.4$ \\
\hline Mean fall in BP (mmHg) & $16.8 \pm 10.4$ & $21.8 \pm 11.4$ & $7.2 \pm 5.4^{*}+$ \\
\hline Percentage of fall (\%) & $17.6 \pm 10.2$ & $22.5 \pm 10.5$ & $7.2 \pm 5.3^{*}+$ \\
\hline Table 3. Change in MBP during the Study (mean \pm SD) \\
\hline
\end{tabular}

*I vs II, +II vs III, p $<0.001$ 
All the patients in the three groups had similar grade of mouth opening, with most of the patients having a fully relaxed jaw. Similarly, ease of LMA insertion was comparable in the three groups. Significantly, a greater number of patients in group I $(n=10)$ and group II $(n=8)$ showed movement on LMA insertion ( $p<0.05)$ compared to group III $(n=2)$. However, none of the patients in either of the groups had any laryngospasm or gagging and coughing.

Patients in group III took maximum time to open eyes (5.9 \pm 0.6 mins) $(\mathrm{p}<0.05)$ compared to group $1(3.9 \pm 0.8$ mins) and group II ( $4.1 \pm 0.1)$. The mean time taken for return of coin counting skills was significantly longer in group III $(p<0.05)$ compared to group I and group II (Table $4)$. The time for discharge was significantly longer in group III compared to group I and group II $(\mathrm{p}<0.05)$.

\begin{tabular}{|c|c|c|c|}
\hline & $\begin{array}{c}\text { Group I } \\
(\mathbf{n = 3 0 )}\end{array}$ & $\begin{array}{c}\text { Group II } \\
(\mathbf{n = 3 0 )}\end{array}$ & $\begin{array}{c}\text { Group III } \\
(\mathbf{n = 3 0 )}\end{array}$ \\
\hline Time for eye opening & $3.9 \pm 0.8$ & $4.1 \pm 0.1$ & $5.9 \pm 0.6^{*}+$ \\
\hline $\begin{array}{c}\text { Time for return of } \\
\text { coin counting skills }\end{array}$ & $62 \pm 28.3$ & $68 \pm 15.6$ & $95 \pm 22.3^{*}$ \\
\hline Time for discharge & $118 \pm 19.1$ & $119.6 \pm 18.6$ & $138.3 \pm 15.3^{*}$ \\
\hline \multicolumn{4}{|c|}{ Table 4. Recovery Profile (mean \pm SD) } \\
\hline
\end{tabular}

*I vs II, +II vs III, $\mathrm{p}<0.001$

\section{DISCUSSION}

The results of our study show that co-induction with a small dose of midazolam provides better haemodynamic stability with least reduction in MAP and HR in patients following induction of anaesthesia with propofol. These findings are consistent with several previous studies.9,10 However, other authors have made different observations. Many studies have found no statistically significant difference in arterial blood pressure between groups receiving midazolam-propofol or propofol alone. $8,11,12,13$ De Lucia and White ${ }^{10}$ and Cressey et $\mathrm{al}^{9}$ have recorded a significantly greater reduction in mean arterial pressure during induction when a combination of fentanyl, midazolam and propofol was used. In our study propofol pre-dosing was associated with greater reduction in arterial pressure than control group, though the difference was not statistically significant. Anderson and Robb ${ }^{8}$ have also observed similar finding and speculated that the control group which received no sedation, maintained a higher sympathetic tone due to anxiety and which was maintained in the initial stages of induction. This is contrary to the observations of Djaiani and Ribes-Pastor ${ }^{6}$ who found maximum reduction in blood pressure in control group. Our results confirm the finding of several authors that a small dose of midazolam given just prior to induction of anaesthesia reduces the requirement of propofol by upto $50 \% .^{7}$ Propofol pre-dosing also reduced the induction dose of propofol as compared to control. Similar observations have been made by a number of authors.6,8 In our study, predosing with midazolam as well as propofol caused a reduction in the dose of induction agent compared to the control group. The dose reduction was significantly more with midazolam pre-dosing $(1.16 \mathrm{mg} / \mathrm{kg})$ compared to propofol pre-dosing $(1.66 \mathrm{mg} / \mathrm{kg})$ and control group $(2.14$ $\mathrm{mg} / \mathrm{kg}$ ). The induction dose of propofol depends on several factors- the end point used, the age of the patient, the rate of infusion and the use of premedication. All these variables were kept constant by enrolling non-premedicated patients, using same end point in all the groups and keeping propofol infusion rate constant at $300 \mathrm{~mL} / \mathrm{h}$.

We found that patients in the midazolam co-induction group took maximum time to eye opening as well as return to coin counting skills and discharge time. In several previous studies, midazolam co-induction has been shown to delay discharge time when psychomotor tests were applied to assess recovery.6,7 Djaiani et $\mathrm{al}^{6}$ have found increase in the discharge time by $2 \mathrm{hrs}$. in the midazolam co-induction group, although no psychomotor tests were performed in their study. In contrast, there are other studies where midazolam co-induction has not been found to cause significant delay in discharge time. ${ }^{10,16}$ De Lucia and White ${ }^{10}$ compared propofol recovery profile with the addition of 2 or $5 \mathrm{mg}$ midazolam during induction of anaesthesia for ambulatory laparoscopy. The high-dose midazolam caused a measurable (mean 15 mins), but statistically insignificant delay in discharge time when compared with low-dose midazolam and control group. In another study, an addition of 0.03 or $0.06 \mathrm{mg} / \mathrm{kg}$ of midazolam to propofol induction did not affect the discharge time after minor gynaecological procedure. ${ }^{16}$ Godsiff et al ${ }^{17}$ have also reported no change in recovery time with the addition of midazolam 2.5 or $5 \mathrm{mg}$. In all these studies, no psychomotor tests were performed to assess discharge readiness. Moreover, different anaesthetic regimen and discharge criteria and lack of definition of discharge times might be other contributing factors.

There was no difference in the degree of mouth opening or ease of LMA insertion among different groups after induction of anaesthesia. There was no significant variation in additional doses of propofol required for ease of LMA insertion between the groups. However, midazolam coinduction was associated with significantly less movement on LMA insertion than propofol co-induction and control groups. Djaiani and Ribes-Pastor ${ }^{6}$ using same anaesthetic technique as used by us have made similar observations. However, in a previous study Driver et al ${ }^{18}$ showed that optimal conditions for LMA insertion in non-premedicated patients were achieved when combination of alfentanil, midazolam and propofol was used. This was associated with better mouth opening and fewer side effects when compared to alfentanil propofol or saline propofol co-induction. The authors used a fixed dose of propofol $1.25 \mathrm{mg}$ for induction of anaesthesia. We used propofol at a constant infusion rate $(300 \mathrm{~mL} / \mathrm{h})$ and used syringe drop technique to titrate the end point of anaesthesia, which has been suggested as being more accurate in defining anaesthetic end point. To achieve this end point a higher dose of $2.03 \mathrm{mg} / \mathrm{kg}$ of propofol was used in propofol-fentanyl group, which might have led to deeper plane of anaesthesia and better suppression of airway reflexes.

\section{CONCLUSION}

Both propofol and midazolam reduce co-induction dose requirements and also a more stable haemodynamics in the midazolam co-induction group was noted compared to propofol pre-dosing group. However, midazolam coinduction delayed psychomotor recovery ( $>20 \mathrm{mins}$ ) when compared to propofol pre-dosing. Therefore, in situations where haemodynamic stability is paramount, midazolam coinduction is a better choice in spite of delayed discharge. 


\section{REFERENCES}

[1] Amrein R, Hetzel W, Allen SR. Co-induction of anaesthesia: the rationale. Eur J Anaesthesiol Suppl 1995;12:5-11.

[2] Fairfield JE, Dritsas A, Beale RJ. Haemodynamic effects of propofol: induction with $2.5 \mathrm{mg} . \mathrm{kg}-1$. Br J Anaesth 1991;67(5):618-20.

[3] Billard V, Moulla F, Bourgain JL, et al. Haemodynamic response to induction and intubation. Propofol/fentanyl interaction. Anesthesiology 1994;81(6):1384-93.

[4] Goodman NW, Black AMS, Carter JA. Some ventilatory effects of propofol as sole anaesthetic agent. $\mathrm{Br} \mathrm{J}$ Anaesth 1987;59(12):1497-503.

[5] Grounds RM, Twigley AJ, Carli F, et al. The haemodynamic effects of intravenous induction. Comparison of the effects of thiopentone and propofol. Anaesthesia 1985;40(8):735-40.

[6] Djaiani G, Ribes-Pastor MP. Propofol auto-coinduction as an alternative to midazolam co-induction for ambulatory surgery. Anaesthesia 1999;54(1):63-7.

[7] Tighe KE, Warner JA. The effect of co-induction with midazolam upon recovery from propofol infusion anaesthesia. Anaesthesia 1997;52(10):1000-04.

[8] Anderson L, Robb H. A comparison of midazolam coinduction with propofol predosing for induction of anaesthesia. Anaesthesia 1998;53(11):1117-20.

[9] Cressey DM, Claydon P, Bhaskaran NC, et al. Effect of midazolam pretreatment on induction dose requirements of propofol in combination with fentanyl in younger and older adults. Anaesthesia 2001;56(2):108-13.
[10] De Lucia JA, White PE. Effect of midazolam on induction recovery characteristics of propofol. Anesth Analg 1992;74:S63.

[11] Tzabar Y, Brydon C, Gillies GW. Induction of anaesthesia with midazolam and target controlled propofol infusion. Anaesthesia 1996;51(6):536-8.

[12] Short TG, Chui PT. Propofol and midazolam act synergistically in combination. $\mathrm{Br} \mathrm{J}$ Anaesth 1991;67(5):539-45.

[13] McClune S, McKay AC, Wright PM, et al. Synergistic interaction between midazolam and propofol. $\mathrm{Br} \mathrm{J}$ Anaesth 1992;69(3):240-5.

[14] Marshall SI, Chung F. Discharge criteria and complication after ambulatory surgery. Anesth Analg 1999;88(3):508-17.

[15] Sikh SS, Dhulia PN. Recovery from general anaesthesia: a simple and comprehensive test for assessment. Anesth Analg 1979;58:324-6.

[16] Elwood T, Huchcroft S, MacAdams C. Midazolam co induction does not delay discharge after very brief propofol anaesthesia. Can J Anaesth 1995;42(2):114-8.

[17] Godsiff L, Magee L, Park GR. Propofol versus propofol with midazolam for laryngeal mask insertion. Eur J Anaesthesiol Suppl 1995;12:35-40.

[18] Driver IK, Wiltshire S, Mills P, et al. Midazolam coinduction and laryngeal mask insertion. Anaesthesia 1996;51(8):782-4. 